University of Nebraska - Lincoln

DigitalCommons@University of Nebraska - Lincoln

$9-21-2001$

\title{
Fabrication of chromium oxide nanoparticles by laser-induced deposition from solution
}

\author{
Z.C. Zhong \\ University of Nebraska - Lincoln \\ R.H. Cheng \\ University of Nebraska - Lincoln \\ Jocelyn Bosley \\ University of Nebraska-Lincoln, jbosley@unl.edu \\ Peter A. Dowben \\ University of Nebraska-Lincoln, pdowben@unl.edu \\ David J. Sellmyer \\ University of Nebraska-Lincoln, dsellmyer@unl.edu
}

Follow this and additional works at: https://digitalcommons.unl.edu/physicssellmyer

Part of the Physics Commons

Zhong, Z.C.; Cheng, R.H.; Bosley, Jocelyn; Dowben, Peter A.; and Sellmyer, David J., "Fabrication of chromium oxide nanoparticles by laser-induced deposition from solution" (2001). David Sellmyer Publications. 192.

https://digitalcommons.unl.edu/physicssellmyer/192

This Article is brought to you for free and open access by the Research Papers in Physics and Astronomy at DigitalCommons@University of Nebraska - Lincoln. It has been accepted for inclusion in David Sellmyer Publications by an authorized administrator of DigitalCommons@University of Nebraska - Lincoln. 
Published in Applied Surface Science, Volume 181, Issues 3-4 (21 September 2001), pages 196-200. Copyright (c) 2001 Published by Elsevier Science B.V.

Used by permission. http://www.sciencedirect.com/science/journal/01694332

\title{
Fabrication of chromium oxide nanoparticles by laser-induced deposition from solution
}

\author{
Z. C. Zhong a, b, c, ${ }^{*}$, R. H. Cheng ${ }^{\mathrm{a}}$, Jocelyn Bosley ${ }^{\mathrm{a}}$, P. A. Dowben ${ }^{\mathrm{a}}$ and D. J. Sellmyer ${ }^{\mathrm{a}}$ \\ ${ }^{a}$ Behlen Laboratory of Physics, Department of Physics and Astronomy and the Center for Materials Research and Analysis (CMRA), Univer- \\ sity of Nebraska, Lincoln, NE 68588-0111, USA \\ ${ }^{\mathrm{b}}$ Institute for Micromanufacturing and Physics Program, P.O. Box 10137, Ruston, LA 71272, USA \\ ${ }^{\mathrm{c}}$ Department of Physics, Grambling State University, Grambling, LA 71245, USA \\ * Corresponding author. Present address: Department of Physics and Astronomy and the Center for Materials Research and Analysis (CMRA), \\ Behlen Laboratory of Physics, University of Nebraska, Lincoln, NE 68588-0111, USA
}

Submitted January 2001; accepted 9 May 2001; available online 16 October 2001.

\begin{abstract}
We have successfully deposited well-dispersed nanoscale chromium oxide particles by laser-induced solution deposition (LISD) from solution with $\mathrm{CrCl}_{2}$ and organic solvents. The particles have narrow distributions about three sizes: 230 , 350 and $400 \mathrm{~nm}$ and are uniform in composition and contain little contamination. We show that LISD is a new technique for producing nanoparticle chromium oxides with uniform composition, controllable size and high yield.
\end{abstract}

Author Keywords: Chromium oxide; LISD; Nanoparticles; $\mathrm{CrCl}_{2}$

Metallic wires and dots can be obtained by reducing a metallic salt in the pores of a membrane. Electrodeposition processes in nanometer-sized pores of aluminum oxide membranes was reported more than 30 years ago [1]. Ultra-dense arrays (reaching $10^{11} \mathrm{~cm}^{-2}$ ) of nanometer-size electrodeposited columns have been successfully produced on substrates made by electron lithography [2]. The use of plastic porous membranes has been extensively investigated and a variety of nano-materials have been successfully made by this method [ 3 and 4 ]. The reduction of metal ions in the membrane creates an assembly of wires, several micrometers in length, with a diameter chosen in the range $30 \mathrm{~nm}$ to a few micrometers [5, 6 and 7$]$.

This is of great interest because magnetic systems of very small dimensions can reveal mesoscopic and quantum effects. Single electron blocking effects have been evidenced in oxidized STM tips or substrates [8], and similar effects were reported in nanowires smaller than $0.01 \mu \mathrm{m}^{2}$ [5]. Initial results on magnetoresistance measurements on nanometer diameter $\mathrm{Ni} / \mathrm{NiO} / \mathrm{Co}$ wires [6] provide evidence of an impurity in the tunnel barrier playing a role in Coulomb blockade [6 and 9], and indeed negative tunnel magnetoresistance might be observed when impurities are present in the barrier [6]. The extension of the Coulomb blockade effect to the ferromagnetic case is at its infancy, but initial measurements [10,11 and 12] and theories [13 and 14] indicate that such systems can show enhanced magnetoresistive properties. An estimate for the spin-flip time $\tau_{\mathrm{SF}}$, deduced from diffusive transport bulk values is of the order of $10^{-12} \mathrm{~s}$. A more relevant time scale for very small metallic particles can be found in the results of Ralph et al. [15 and 16] using the discrete electronic states of Al 
nanoparticles. They gave an estimate of $10^{-8}-10^{-9} \mathrm{~s}$ for the relaxation rate of excited states. Making nanoscale particle of ferromagnetic and antiferromagnetic particles is the key to future research in this area.

Chromium oxides have attracted much attention recently because of their importance both in science and technology. Band-structure calculations [17] predict that $\mathrm{CrO}_{2}$ is a half-metallic ferromagnet - a system which is metallic for one spin direction and insulating for the opposite spin direction. This contention is supported by reflectivity measurements [18] and Andreev scattering [19 and 20]. Unfortunately, it is very difficult to fabricate $\mathrm{CrO}_{2}$ nanoparticles by using conventional methods due to the high temperatures required and the metastablity of $\mathrm{CrO}_{2}$ phase, nor there has been much success with the fabrication of nanoparticles in the antiferromagnetic insulating $\mathrm{Cr}_{2} \mathrm{O}_{3}$ phase.

Laser-assisted deposition from solution is clearly compatible with electrochemical deposition. The laser-assisted deposition from solution (LISD) techniques has been successfully used to deposit $\mathrm{ReB}_{6}$ $(\mathrm{Re}=$ rareearthmetal) [21, 22, 23 and 24], copper [25 and 26], palladium [27 and 28] and more complex materials like $\mathrm{LaNiO}_{3}$ [29]. Laser assisted deposition from a solution of silver nitrate was also used to deposit silver clusters [30]. In both the deposition of copper and palladium from solution, the metal source was a chloride [25, 26, 27 and 28], as the case in this work. We have applied this technique to fabricate nanoparticles of chromium oxide.

The deposition of chromium oxides by laser-induced solution deposition (LISD) was carried out with the laser operating in a CW mode, for which we employed an argon ion laser (the Coherent Innova 90 Series Ion Laser). $\mathrm{CrCl}_{2}$ and $\mathrm{Cr}(\mathrm{CO})_{6}$ dissolved in solutions containing various mixtures of methanol, cyclohexane, tetrahydrofuran (THF), and diethylether. Mixtures of solvents were originally chosen on the basis of solvent PkA, but minimization of solvent absorption of the light proved to be an important criteria. While the methanol or small amounts of "dissolved" water are believed to be a key source for oxygen in the deposition and formation processes for chromium oxides, without isotopic exchange experiments, proof is elusive. Without drying, THF contains dissolved $1-2 \%$ water. The deposition time in this experiment varies from 0.5 to $24 \mathrm{~h}$ and neither the samples nor the laser beam were translated during the experiment relative to one another. Both visi- ble (laser power: 5-7 W and wavelength: $514 \mathrm{~nm}$ (457$528 \mathrm{~nm}$ )) and UV radiation (laser power: $10-100 \mathrm{~mW}$ and wavelength: $351 \mathrm{~nm}$ ) were used in the experiment. The substrates for deposition were Si (llll 111$)$ wafers or soda-glass in all the experiments.

While the oxidation of $\mathrm{Cr}(\mathrm{CO})_{6}$ to $\mathrm{CrO}_{2}$ and $\mathrm{Cr}_{2} \mathrm{O}_{3}$ has been successful in the gas phase [31 and 32], we did not find this source compound effective in solution deposition at room temperature. The chemical vapor deposition of $\mathrm{Cr}_{2} \mathrm{O}_{3}$ has also been successfully demonstrated using $\mathrm{Cr}(\mathrm{acac})_{3}$ [33] while deposition of highly spin-polarized $\mathrm{CrO}_{2}$ has been successfully deposited by photolysis of chromyl chloride [34 and 35]. By trial and error, we found that chromium oxides could be deposited on Si ( $\left.\begin{array}{lll}1 & 1 & 1\end{array}\right)$ and soda-glass substrates from $\mathrm{CrCl}_{2}(2.0 \mathrm{mg})$ dissolved in solvent mixtures of $1.5 \mathrm{ml}$ THF and $1.5 \mathrm{ml}$ cyclohexane with the laser tuned to the visible region with laser power at about $5 \mathrm{~W}$ and wavelength at $514 \mathrm{~nm}$. Under conditions of low fluence, nanoparticles were formed (Fig. 1a) without chlorine contamination (Fig. 1c). At high fluence, deposition resulted in more uniform deposits ( Fig. 1b) but include chlorine contamination and no chromium containing particles. Uniform particle sizes more readily form on silicon substrates.

As shown in Fig. 1a, with low laser fluence, the resulting deposited chromium oxide the nanoparticles are quite uniform in size and shape. After $12 \mathrm{~h}$ deposition, the particle sizes are narrowly distributed in sizes about 230, 350 and $400 \mathrm{~nm}$ or deposits that are near integer multiples of $4 \times 10^{4} \mathrm{~nm}^{2}$. This is shown in Fig. 1d, where plot the particle diameters, and it is clear that the diameters fall close to $230, \sqrt{2}$ (or $\sim 1.4 \times$ ) 230 and $\sqrt{3}$ (or $\sim 1.7 \times$ ) $230 \mathrm{~nm}$. We suggest these narrow, and widely spaced particle sizes are a result of one, two and three nucleation sites on the substrate surface: possibly catalytically active sites for the redox reaction of $\mathrm{CrCl}_{2}$ in solution. This is one of the first examples of such uniform nanoscale $\mathrm{CrO}_{x}$ particles. The dominant role of defects in the island size distribution and island growth overlayers has been observed in other systems $(\mathrm{Pd}$, for example) grown on other insulators $(\mathrm{MgO})$ [36], and the particle distribution sizes do not cover the wide range observed with the formation of silver particles from laser-induced deposition from solution reported elsewhere [30]. The difficulty with the technique is that the $\mathrm{CrO}_{x}$ particles do not appear to be a necessarily single phase oxide. 


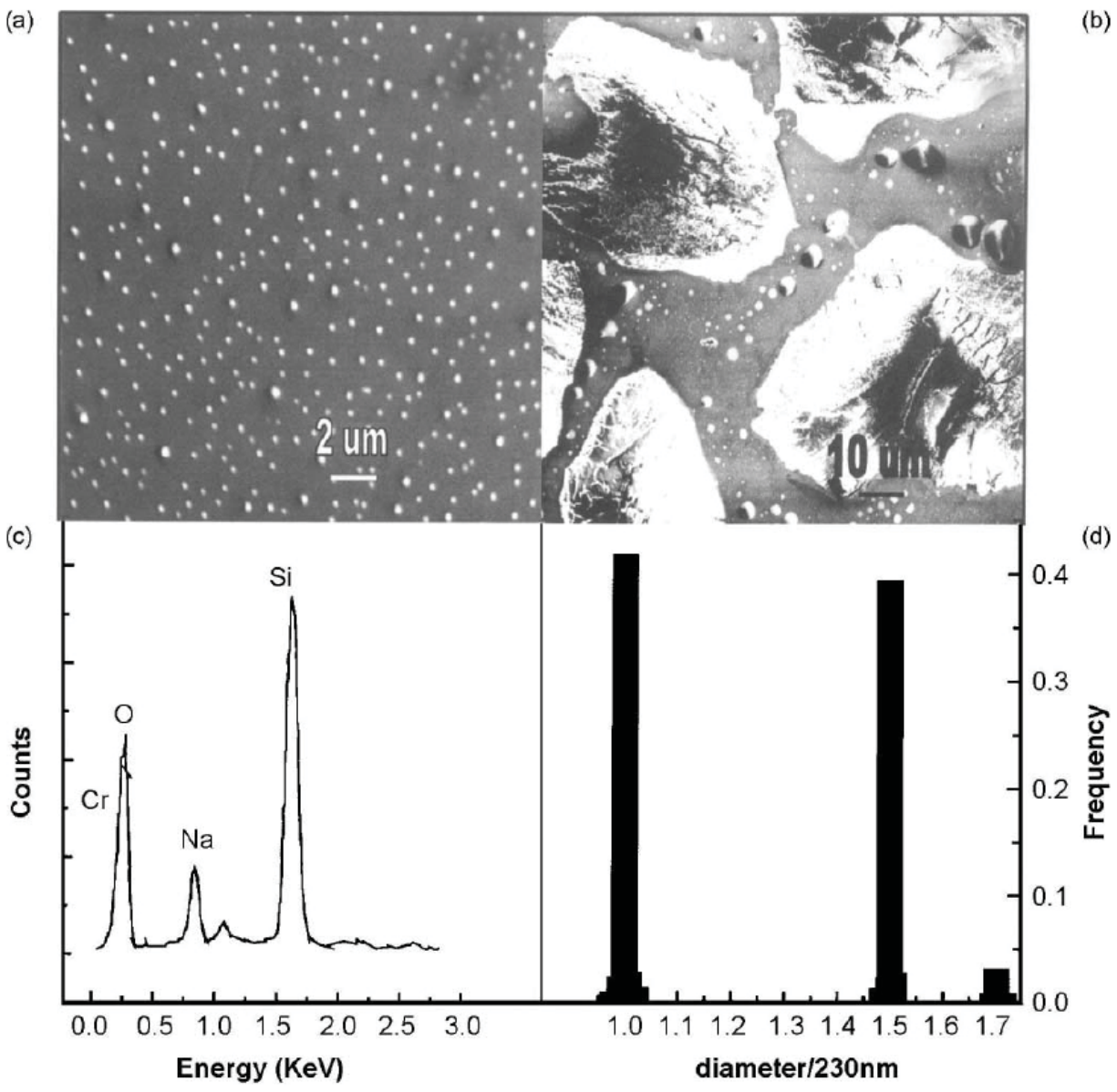

Fig. 1. (a) SEM image of $\mathrm{CrO}_{x}$ nanoparticles on soda-glass substrates obtained by LISD (wavelength at $514 \mathrm{~nm}$; laser beam exposure area was about $10 \mathrm{~mm}$; solute was $\mathrm{CrCl}_{2}(2.0 \mathrm{mg})$ dissolved in solvents $1.5 \mathrm{ml}$ THF and $1.5 \mathrm{ml}$ cyclohexane) with a deposition time of $12 \mathrm{~h}$. The common particle size $\left(\mathrm{CrO}_{x}\right)$ was about $230 \mathrm{~nm}$ diameter as well as those twice or three times in area. (b) SEM image of $\mathrm{CrO}_{x}$ films on soda-glass substrates obtained by LISD (wavelength at $514 \mathrm{~nm}$; laser beam exposure area was about $10 \mathrm{~mm}$; solute was $\mathrm{CrCl}_{2}(2.0 \mathrm{mg})$ dissolved in solvents $1.5 \mathrm{ml} \mathrm{THF}$ and $1.5 \mathrm{ml}$ cyclohexane) under conditions of high fluence. (c) Shows the EDAX spectra of the $\mathrm{CrO}_{x}$ nanoparticles as in (a). Chlorine contamination was absent and strong oxygen and chromium signals are present. (d) Shows the distribution of particle diameters relative to $230 \mathrm{~nm}$.

As seen in Fig. 2, the X-ray diffraction of the nanoparticles deposited on silicon are dominated by two highly textured phases. The particles consist mostly of thermodynamic sink for chromium oxide, $\mathrm{Cr}_{2} \mathrm{O}_{3}$, with strong (1 22 2) orientation (the diffraction line at 58.82). The lattice constant is slightly deformed, suggesting about $0.5 \%$ compressive strain. There is also a minority chromium oxide phase that could be $\mathrm{Cr}_{3} \mathrm{O}_{8}, \mathrm{Cr}_{2} \mathrm{O}_{5}$ or $\mathrm{Cr}_{8} \mathrm{O}_{21}$ with strong texture growth along the $\left(\begin{array}{lll}0 & 1 & 1\end{array}\right)$ direction in all cases. Given the small volume of the nanoparticles and similar chromium to oxygen ratio for these chromium oxides, further measurements along the lines of micro-spot near edge X-ray adsorption spectroscopy are indicated.

In summary, we have successfully demonstrated that LISD is an efficacious fabrication method for producing nanoscale $\mathrm{CrO}_{x}$ particles. The advantages of the technique is the very low processing temperatures, and the compatibility with electrochemical deposition methods. 


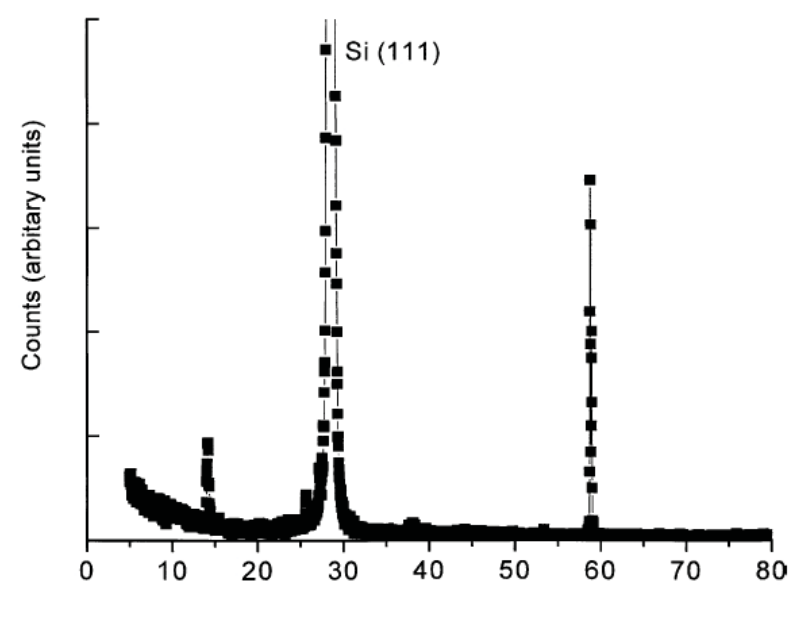

$2 \theta$

Fig. 2. The substrate silicon $\theta-2 \theta$ line dominates the X-ray diffraction but $\mathrm{Cr}_{2} \mathrm{O}_{3}$, with strong (1 2 2) orientation, is apparent in the diffraction line at $58.82^{\circ}$. There is also a minority chromium oxide phase that could be $\mathrm{Cr}_{3} \mathrm{O}_{8}, \mathrm{Cr}_{2} \mathrm{O}_{5}$ or $\mathrm{Cr}_{8} \mathrm{O}_{21}$ with strong texture growth along the $\left(\begin{array}{lll}0 & 1 & 1\end{array}\right)$ direction in all cases, with a diffraction line at about $14.15^{\circ}$.

\section{Acknowledgements:}

This work was supported by the Office of Naval Research, the Center for Materials Research and Analysis (CMRA) and the Nebraska Research Initiative at the University of Nebraska.

\section{References}

1. S. Kawai and R. Ueda. J. Electrochem. Soc. 122 (1975), p. 32.

2. S.Y. Chou, P. Krauss and L. Kong. J. Appl. Phys. 79 (1996), p. 6101.

3. C.R. Martin. Science 266 (1994), p. 1961.

4. C.R. Martin. Chem. Mater. 8 (1996), p. 1739.

5. G. Redmond, S. Gilbert, B. Doudin, J.-Ph. Ansermet, Electrochemical synthesis and modification of materials, MRS Symp. Proc. (1997) 377.

6. B. Doudin, S. Gilbert, G. Redmond and J.-Ph. Ansermet. Phys. Rev. Lett. 79 (1997), p. 933.

7. J.E. Wegrowe, S.E. Gilbert, D. Kelly, B. Doudin and J.-Ph. Ansermet. IEEE Trans. Magn. 34 (1998), p. 903.

8. R. Wilkins, M. Amman, E. Ben-Jacob and R.C. Jaklevic. Phys. Rev. B 42 (1990), p. 8698.

9. H. Grabert, M.H. Devoret, NATO ASI Series, Plenum Press, New York, 1991.

10. K. Ono, H. Shimade, S. Kobayashi and Y. Ootuka. J. Phys. Soc. Jpn. 65 (1996), p. 3449.
11. L.F. Schelp, A. Fert, F. Fettar, P. Holody, S.F. Lee, J.L. Maurice, F. Petroff and A. Fert. Phys. Rev. B 56 (1997), p. 5747.

12. A. Brataas, Yu.V. Nazarov, J. Inoue and G.E.W. Bauer. Phys. Rev. B 59 (1999), p. 93.

13. S. Takahashi and S. Maekawa. Phys. Rev. Lett. 80 (1998), p. 1758.

14. J. Barnas and A. Fert. Phys. Rev. Lett. 80 (1998), p. 1058.

15. D.C. Ralph, C.T. Black and M. Tinkham. Phys. Rev. Lett. 74 (1995), p. 3241.

16. D.C. Ralph, C.T. Black and M. Tinkham. Phys. Rev. Lett. 78 (1997), p. 4087.

17. K. Schwarz. J. Phys. F 16 (1986), p. 211.

18. H. Brandle, D. Weller, J.C. Scott, J. Stichit, P.M. Oppeneer and G. Guntherodt. Int. Mod. Phys. 7 (1993), p. 345.

19. R.J. Soulen, et al., Science 282 (1998) 85.

20. R.J. Soulen, M.S. Osofsky, B. Nadgorny, T. Ambrose, P. Boussard, S.F. Cheng, C.T. Tanaka, J. Nowack, J.S. Moodera, G. Laprade, A. Barry and M.D. Coey. J. Appl. Phys. 85 (1999), p. 4589.

21. Z.C. Zhong, P.A. Dowben and D.J. Sellmyer. Mater. Lett. 37 (1998), pp. 320-324.

22. Z.C. Zhong, V. Holmes, P.A. Dowben, D.J. Sellmyer, Flatpanel displays and sensors - principles, materials and processes, in: B.R. Chalamala, R.H. Friend, T.N. Jackson, F.R. Liebsch (Eds.), Proceedings of the Symposium of Materials Research Society, Vol. 558, 2000, pp. 9196.

23. P.A. Dowben, Z.C. Zhong, D.J. Sellmyer, US Patent 6025038 (2000). 
24. P.A. Dowben, Z.C. Zhong, D.J. Sellmyer, US Patent 6077617 (2000).

25. S.D. Hwang, S.S. Kher, J.T. Spencer, P.A. Dowben, Chemical perspectives of microelectronic materials III, in: C.R. Abernathy, C.W. Bates, D.A. Bohling, W.S. Hobson (Eds.), Proceedings of the Symposium of Materials Research Society, Vol. 282, 1993, p. 186.

26. S.-D. Hwang, S.S. Kher, J.T. Spencer, P.A. Dowben, in: K.L. Mittal (Ed.), Metallized Plastics 4: Fundamental and Applied Aspects, Marcel Dekker, New York, 1997, pp. 9-14.

27. J. Békési, K. Kordás, Cs. Beleznai, K. Bali, R. Vajtai and L. Nánai. Appl. Surf. Sci. 138-139 (1999), p. 613.

28. K. Kordás, K. Bali, S. Leppävuori, A. Uusimäki and L. Nánai. Appl. Surf. Sci. 152 (1999), p. 149.

29. C.R. Cho, D.A. Payne and S.L. Cho. Appl. Phys. Lett. 71 (1997), p. 3013.

30. R. Subramanian, P.E. Denney, J. Singh and M. Otooni. $J$. Mater. Sci. 33 (1998), p. 3471.

31. K. Perkins, C. Hwang, M. Onellion, Y.-G. Kim and P.A. Dowben. Thin Solid Films 198 (1991), pp. 317-329.

32. R. Cheng, C.N. Borca, P.A. Dowben, S. Stadler and Y.U. Idzerda. Appl. Phys. Lett. 78 (2001), p. 521.

33. S. Chevalier, G. Bonnet and J.P. Larpin. Appl. Surf. Sci. 167 (2000), p. 125.

34. W.J. Desisto, P.R. Broussard, T.F. Ambrose, B.E. Nadgomy and M.S. Osofsky. Appl. Phys. Lett. 76 (2000), p. 3789.

35. C. Arnone, M. Rothschild, J.G. Black and D.J. Ehrlich. Appl. Phys. Lett. 48 (1986), p. 1018.

36. G. Haas, A. Menck, H. Brune, J.V. Barth, J.A. Venables and K. Kern. Phys. Rev. B 61 (2000), p. 11105. 